\title{
Ethical Principles for the Conduct of Human Subject Research: Population-Based Research and Ethics
}

Lawrence O. Gostin

Georgetown University Law Center, gostin@law.georgetown.edu

This paper can be downloaded free of charge from:

https://scholarship.law.georgetown.edu/facpub/764

19 L. Med. \& Health Care 191-201 (1991)

This open-access article is brought to you by the Georgetown Law Library. Posted with permission of the author. Follow this and additional works at: https://scholarship.law.georgetown.edu/facpub

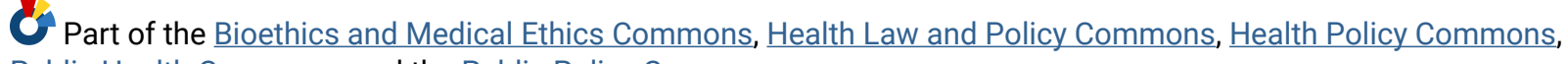




\title{
Ethical Principles for the Conduct
}

\section{of Human Subject Research:}

\section{Population-Based Research and Ethics}

\author{
Larry Gostin
}

Ethical principles for the protection of human subjects in clinical research are now well recognized,' and rooted in the inherent worth and dignity of the individual.

Respect for persons recognizes people as autonomous agents and requires that their choices be observed. For persons who are not fully autonomous, the principle of respect for persons requires that they are protected from risks and adverse consequences of research, even sometimes excluded from research.

Beneficence (do good) and non-maleficence (do no harm) are complementary ethical principles that impose affirmative duties on researchers to maximize any benefits for subjects and minimize any risks. Thus, researchers must go beyond mere respect for a person's choices. The researcher must be vigilant to ensure that the subject receives all possible benefits and avoids all possible harms from participating in the research.

Justice requires that human beings be treated equally unless there is a strong ethical justification for treating them differently. Thus, the distribution of benefits and burdens in research should be equitable. In thinking about justice toward subjects, researchers need to consider equitable selection so that individuals are chosen on the basis of factors clearly relevant to the problems being studied. Researchers also need to consider equitable distribution of advantages to research subjects and others who could benefit from the knowledge gained by the research.

These ethical principles have found expression in international guidelines for the conduct of clinical research ${ }^{2}$, and have been codified in national statutes and regulations, particularly in the developed world. ${ }^{3}$

Ethical principles help support autonomy and selfdetermination, protect the vulnerable, and promote the welfare and equality of human beings. But traditional ethics focuses primarily on individual rights and duties, and does not always see individuals as part of wider social orders and communities. A person dominated medical ethic is insufficient for the task of setting moral and human rights boundaries around the conduct of research on populations.

This paper provides a halting first step in organizing a set of ethical guidelines for the conduct of populationbased research, surveillance and practice. These principles are not distinct from, but an expansion of, traditional ethics. Research ethics, which matured significantly from the Nuremberg Code through to the Helsinki IV and the CIOMS guidelines, nourished the individual human spirit. Ethical principles should have a similarly profound impact in the development of science and the protection of human populations in the r 990 s and beyond.

\section{The application of ethical principles to populations}

Ethical principles applied to larger groups of people or populations are designed to protect the human dignity, integrity, self-determination, confidentiality, rights, and health of populations and the people comprising them. The kinds of social groupings encompassed in this definition include communities, cultures, social orders, and populations of various description including racial, ethnic, religious, cultural, and other minorities. Ethical principles also establish positive moral responsibilities of persons and authorities which sponsor, conduct, or oversee research on populations. This includes governments, funders, and investigators in the country which embarks on the research as well as the country which hosts the research. 
The importance of group identity, and of treating social communities with dignity and respect, is increasingly well recognized. Human beings gain security, happiness, and enjoyment by forming networks based upon their special national or sub-national characteristics. ${ }^{4}$ Respect and beneficence for populations requires researchers to observe choices made by local communities, and to avoid any activity which stigmatizes, demeans, harms, or disintegrates human populations, intentionally or inadvertently.

The term "population-based research" is broadly defined to include all research and practice performed on, or which affects, groups of people or populations. This includes epidemiologic research and surveillance, and intervention epidemiology, including field trials for drugs or vazcines.

Population based research, surveillance, and practice can have extraordinary benefits and risks. The potential for human good, measured in improvement of health and decreased morbidity and mortality from population-based research and practice represents one of the great triumphs of science in the 2oth century. But, the potential to cause harm to human beings and the groups they comprise is also much greater.

Population-based research and practice affect not only individual research subjects but integrated groups of people, sometimes of considerable size. This can entail large scale collection, storage, transfer, and use of sensitive health care, demographic, social, and behavioral data. Modern field trials can also actively intervene in the behaviors, lifestyles, social and family interactions, or environments, of communities. Levine provides illustrations of risks to societies such as introduction of a new microorganism, spread of infection to persons outside the trial, and premature or inappropriate dissemination of findings or opinions of researchers which may result in harmful changes in behavior, false hopes for cures, or lowered selfimage.'

Foundational principles must also be developed to protect the dignity and integrity of all populations including vulnerable populations which are non-dominant, poor, disenfranchised, compromised, persecuted, or restricted. This paper enunciates five such principles: (i) the overriding imperative to protect the health and well-being of populations, (ii) respect for populations and their right to self-determination, (iii) protection of vulnerable populations and the need for special justifications for research, (iv) protecting the privacy, integrity, and self-esteem of populations, and (v) the equitable distribution of benefits to populations and the importance of building infra-structure.

\section{First do no harm}

The Geneva Declaration does not specifically cover human subject research, but restates the first principle of medicine enunciated in the Hippocratic oath-a doctor's first duty is to his or her patient.6 In the context of population-based research the investigator has a dual responsibility to individual subjects and to the populations they are part of. The first principle in this area of ethics is not to harm the subject population.

The duty not to harm is grounded in the principles of beneficent treatment of, and respect for, populations. Application of the principle of beneficence toward individuals in biomedical research often is measured by a favorable benefit to harm ratio. The potential benefits of a new pharmaceutical or vaccine must be well understood from laboratory models, the risks must be reasonable, and the adverse effects must be carefully monitored and controlled.

Beneficence toward populations certainly requires a favorable balance of potential benefits and harms. But, the concern is not merely with the physical health of the human subject, but also with the potential benefits and harms to the group or culture that is being studied. Human subjerts, for example, may be medically protected, but the research may be of little value to, or reflect poorly on, the group to be studied.

A prerequisite of ethical research is that it is based upon a sound objective recognized as a priority in the country to be studied. The research, therefore, should be clearly relevant to the public health problems in the local community. Is it ethically justified to conduct research in a host country for the overwhelming benefit of another country? Research of intrinsic scientific value or a value established in one country may not be valid if conducted in another country which has little interest in, or need for, that scientific information. Research to address a pressing public health problem in developed countries (e.g. coronary heart disease) may be irrelevant in developing countries which may be more concerned with diarrheal disease and maternal-child health. If the preponderant benefits of a study are in the source, rather than in the host country, a strong justification would have to be made to initiate the research.?

The ethical question is not only whether the research is needed in the host country, but also whether it is wanted. Respect for populations suggests that representatives who can legitimately speak for the people ought to have control over whether, and how, research is conducted, and how the outcomes of research are distributed and used to benefit the population.

Good science is always an overarching requirement of ethical research. The quality of research is established where the scientific protocol is reviewed in both countries using processes that are developed in culturally and legally appropriate ways in each country. Good scientific research, wanted and reviewed by all relevant parties, ultimately provides the best protection for human populations. 
Respect for people and populations: Individual consent, permission and community consensus

The focus on individualism in traditional ethics is most clear when the principle of respect for persons is examined. The primary way to respect individuals is to abide by their choices, whether or not others believe their choices are wise or beneficial. "To show lack of respect for an autonomous agent is to repudiate that person's considered judgments, to deny an individual the freedom to act on those considered judgments, or to withhold information necessary to make a considered judgment." ${ }^{\prime}$ Autonomy and self-determination are illuminated by the antagonistic principle of paternalism, where decisions are made for, not by, individuals because others know better what is in that person's interests.

Since the Nuremberg Code, international human rights declarations have focused on autonomy rather than paternalism. International law perceives individuals as capable of exercising the power of choice. People must be free to decide whether to participate in research or to withdraw their participation without any influence of coercion, fraud, deceit, or constraint.9 Helsinki $\mathrm{IV}^{\mathrm{ro}}$ and the CIOMS Proposed Biomedical Research Guidelines ${ }^{\text {i }}$ focus on the need for advance information on research methods, objectives, benefits, and risks to allow an informed choice.

Autonomy and individual consent are invaluable principles which allow competent persons to keep control over health and research decisions. Ethical research always places the desires and needs of the subject over those of the investigator. ${ }^{12}$ The principle of consent thus helps prevent abuse by overzealous governments or researchers who are sometimes under great pressure to conduct expeditious and successful research into the overwhelming health problems facing both developed and developing countries.

The limits of consent as a method of preserving human dignity and health, however, are increasingly well understood. As a safeguard against abuse consent is, at best, an imperfect instrument. Informed consent, even in developed countries which originated the doctrine, is an ideal which does not always work in practice.'3 The inequality of expertise and influence between researcher and subject can be so great as to undermine the real authority of subjects to withhold or withdraw consent. Innumerable problems can interfere with a truly informed and voluntary relationship between clinician/investigator and patient/subject: the fine line between therapeutic practice and scientific research; the lack of access to innovative treatments outside of established clinical trials; the payment of money or other inducements to enter and remain in research; the differences in linguistic and cultural understandings between researchers and human subjects; and the sheer complexity of written informed consent forms often thought necessary or expedient for the purposes of the legal system.

Thus, even in well developed countries where the legal system and culture foster the concept of informed consent, practical realities may impede voluntariness and effective communication between researcher and subject. This is particularly true when research is undertaken in urban ghettos or poor rural areas where problems of illiteracy, and mistrust based upon race, culture, or social class may undermine the researcher/subject relationship.

The practical obstacles to obtaining voluntary and informed consent in international collaborative research are even more evident: the marked inequality of power and resources; the vast differences in law and culture; and the pressing problems of disease, hunger, illiteracy, and poverty. ${ }^{14}$

Law and regulation in technologically developed countries may require detailed written informed consent for participation in research even if it is conducted in another country with different laws and customs. ${ }^{15}$ Regulators in parts of the developed world sometimes forget that written documentation is merely evidence of the consent, not the consent itself, and that documentation is an alien concept in many cultures. Requiring a person who may be illiterate and whose first language may be different to comply with Northern/Western conceptions of written informed consent is unrealistic.

In some communities the very concept of respect for persons as individuals may be at variance "with more relational definitions of the person found in other societies... which stress the embeddedness of the individual within society and define a person by his or her relations to others." ${ }^{16}$ In some cultures there is little perception of conflict between self and society, except perhaps if the society is someone else's."' For example, in the Indian subcontinent and West Africa great deference may be given to clinicians/healers/elders. ${ }^{18}$ Decisions are characteristically made in consultation with leaders in the setting of village meetings. ${ }^{19}$ If permission has already been given by a community or family representative, the idea of an informed refusal by the individual may not even arise. Henderson et al. found that obedience to tribal leaders is a strong factor influencing participation in research in West Africa. ${ }^{2 \circ}$ Where indigenous cultural beliefs exist the research may take on a wholly different meaning in the local country than the Northern scientist understands. ${ }^{21}$ Ajayi illustrates this point with the socio/cultural/religious beliefs in West Africa regarding blood letting, biopsy, and postmortem examinations.

Giving impoverished people in the developing world money, drugs, and food in exchange for their agreement to enter and remain in clinical trials may make it inconceivable that they would say no. ${ }^{22}$ Yet, providing reasonable compensation to impoverished subjects who may have to take time from life sustaining work is entirely justified. 
Despite the real problems of importing a Northern/ Western concept of informed consent in Third World countries, some culturally appropriate agreement to participate in research is essential. "While consent procedures must be adapted to accommodate cultural mores, there must always be a requirement for consent from the individual prospective subject." ${ }^{23}$ It is false to equate illiteracy or cultural differences with the inability to make decisions. Information should be presented to subjects in a manner which is comprehensible and consistent with local language, custom and culture. It is equally incorrect to assume that an individual's strong relationship with family and society are inconsistent with informed consent. The fact that individuals, in deciding whether to give consent, give deference to the views of family and community leaders, and carefully consider the benefits to society, does not negate their consent.

The CIOMS Proposed Guidelines on Biomedical Research $^{24}$ recommend that, if a person cannot give adequate informed consent, it is desirable to obtain proxy consent through the intermediary of a trusted community leader, ${ }^{25}$ While it may be important to recognize the cultural importance of community or family leaders, it is unwise to refer to this process as a consent. It is more accurately labeled as "permission." The leader may represent the interests of the community more than the individual and may him or herself be susceptible to inducements which undermine the purpose of consent.

Large scale research raises a further issue as to how consent is given on behalf of the population. Specifically, can a legitimate representative of the community give consent on behalf of each of its members? Clearly, community leaders cannot realistically give consent on behalf of the entire population, for they have no way of knowing what decision each person would make. "Consent" is the wrong concept because each of the traditional elements is lacking: specific information on benefits and risks, voluntariness, and competency. A better conception is to say that leaders ought to be consulted to obtain a "community consensus" on population-based research.

In many situations it may be difficult to ascertain who is the legitimate representative of the community. Governments or public health agencies may, or may not, be elected by the people and have their rights and best interests at heart. Some leaders have no formal or recognized legal authority to speak for the population, but may be widely lonked to as religious, cultural or social representative of the people. In seeking community consensus for large scale research, investigators must be knowledgeable of, and sensitive to, local perceptions of those who are in true leadership positions.

It would be antithetical to all understanding of human rights to suggest that a leader could give "permission" for an individual or provide "consensus agreement" for the community, as a substitute for individual consent. Rather, researchers have an ethical obligation to seek consent from the individual, as well as permission or consensus, when culturally appropriate. Thus, the inter-related concepts of individual consent, permission, and consensus should be regarded as additive ethical obligations which are to be examined within the context both of international human rights norms and local cultural and ethical beliefs.

An effective model of consent, permission and consensus has been reported by Hall in Gambia. Individual agreement is sought through a hierarchical chain beginning with the government, then moving to the chief of the district, and to the head of the village. Village meetings are held to explain the study, and each individual is asked if he or she agress to the study in his or her household. ${ }^{26}$

\section{Protection of vulnerable people and populations}

Not every human being can give a competent and voluntary consent to research. Some people have diminished autonomy due, for example, to young age, mental illness or mental retardation. Others, such as prisoners, or, in some countries, the military, are so impeded in their freedoms and so subject to authority, that their consent is not entirely voluntary. For some individuals such as pregnant women, there can be increased risks associated with research; the woman herself may be subjected to heightened risk due to her condition, and the fetus may be unnecessarily exposed to harm. Respect for people with diminished capacity, those who are not entirely free to choose, or those with a heightened risk may require protection from potential harms of research. People may be so vulnerable that strict criteria must apply before they can even participate in a clinical trial.

Traditional micro-ethical principles, therefore, require a special justification before research is conducted on vulnerable individuals. In general, vulnerable subjects are selected only if the research is directly relevant to the person or class of persons-e.g., the very issue to be studied is prevalent in, or unique to, the group. ${ }^{27}$

Ethical principles would similarly require a special justification for research on vulnerable populations. Vulnerable populations could be defined as a class of individuals or groups who are non-dominant, subst rvient, or subject to restrictions in the culture where thry live. It could include a minority race, religion, ethnic group, indigenous people, or aliens. These groups may have retained social, cultural, economic and political characteristics which are distinct from those of other segments of national populations. ${ }^{28}$ Examples of epidemiologic research on nondominant social groups include studies of prostitutes for sexually transmitted infections, drug users for needle-borne infections, women and children for vertical transmission of disease, and gays or hemophiliacs as risk groups for HIV 
infection. Vulnerable populations might also include persecuted non-minorities such as women in cultures where they are wholly subservient to their spouses.

Non-dominant populations should be regarded as vulnerable for much the same reasons that apply to individuals. Non-dominant populations are inherently likely to be exploited. Poverty makes a population more susceptible to financial or other inducements; their culturally or politically insular position may undermine their autonomy and ability to resist the suggestion of authorities that they participate in research; their illiteracy and lack of adequate communication networks makes it difficult to disseminate comprehensive and comprehensible information; their hunger and poor health may heighten the risks and burdens of research. Under such circumstances, the principles of respect and beneficence toward populations militates against imposing burdens without a special justification.

\section{Special circumstances justifying research on vulnerable groups}

What are the special circumstances that might justify research on vulnerable groups? A particularly favorable benefit to burden ratio would be one prime factor. If it could be established that the health advantages to the population clearly outweigh the minimal risks or burdens, this would help protect the population.

Second, the problem to be studied should be clearly relevant to the unique or special health problems of the population. A study of tropical disease, for example, in an endemic area may be completely justified, even though the population is highly vulnerable. The principle of justice, of course, would require that the vulnerable population has access to the present and future benefits of the research.

Third, every effort should be made to maximize the rights of the population to self-direction and protection from harm. The voices of vulnerable populations should be heard and respected not only on issues of subject selection, but also on the ethical conduct and outcomes of the research. Thus, genuine representatives of the population (as well as the individuals who comprise the population) must agree to participate, must have the right to withdraw at any time, and must be consulted in the use of the information generated from the study. If the study may cast aspersions on, or in some way disintegrates, the community, this must be discussed as part of the process of consent, permission, and consensus.

The relevant criteria, then, are whether there is a favorable benefit to burden ratio, whether the problem is relevant to the special health problems of the population, and whether the population chooses the research. To many, however, research may be justified when it provides a potential for overwhelming benefit for humankind, even if the benefit to the research population is in doubt. Consider the real ethical quandary over HIV anti-viral or vaccine research in Africa, particularly if undertaken on especially vulnerable groups such as prostitutes. Field trials may be accomplished more expeditiously in endemic areas because of the greater incidence of infection. The scientific advantages are that reliable results could be obtained more quickly and at less expense. The local population, however, may never see the benefit of a safe and efficacious drug or vaccine due to the prohibitive cost, and an expensive anti-viral might be low on the health care priorities of the host country. Similarly, in : vaccine trial for HIV, beneficent treatment of persons would require that subjects were counselled to avoid high risk behavior. This would undoubtedly result in a relativaly smaller measured influence, requiring a larger sample size to demonstrate the efficacy of the vaccine.

Cost and expediency alone are seldom sufficient ethical justifications for subject selection. The key questions are how much benefit and harm might accrue to the population? Are there adequate laboratory or animal models to predict efficacy and risk? What are the reasons that other, less vulnerable, subjects cannot be used, and can they be used in parallel?

\section{First World research in Third World countries}

In international collaborative research First World investigators conduct research in poorer Third World countries. Because of the inherent inequality in economic and political power, these local communities may also be thought of as vulnerable populations and subjected to ethical rules that are similar to those applied to vulnerable individuals and groups within the same country. It is a legitimate ethical inquiry to ask why investigators choose to do their research abroad rather than at home. First, and most cynically, governments, sponsors and investigators may be prepared to impose risks and burdens on Third World populations which they are reluctant to impose on their own populations. A particularly risky, intrusive, or politically controversial piece of research may be perceived to be easier to conduct thousands of miles from home. A key international principle for research on human beings is that "a nation should not allow or support, in other countries, research which does not conform to ethics review standards at least equivalent to those in force within the nation." 29 Clearly, if research could be conducted as effectively on home populations, there should be special justifications before carrying it out on poorer populations abroad. Indeed, similar reasoning would prohibit research on the poor, illiterate, and unhealthy dweller of the ghetto if the research could just as effectively be carried out in an affluent suburb.

Second, researchers might choose poorer populations for their research because of financial, management, and 
administrative teasons. A Third World population may be regarded as more available, manageable, and less expensive than in a developed country. Naked financial or administrative considerations are rarely sufficient justifications for imposing risks and burdens on poorer populations. However, if appropriate subjects in the dominant populations have been saturated, some believe it is appropriate to utilize more vulnerable populations. Whether a recruitment problem itself provides a sufficient justification for research on non-dominant populations depends upon the context.

Third, the conditions in Third World populations may result in higher seroprevalence and greater incidence of transmission of disease. Clearly a study conducted under such conditions might be completed more quickly and more reliably, providing some justification for the decision. But, if populations at home have similar characteristics, they would be more appropriate subjects for research.

The overriding justification for research in Third World countries is that the disease studied is either rare or non-existent in the country of origin. This justification is as rigorous as that used for research on vulnerable individuals and groups within a country. The ideal circumstances for international collaborative research are when the scientific inquiry is focused on a genuine health problem of the local population, there is a low risk and a good prospect of benefit to the research subjects, and the outcome of the research will be available to promote the health of Third World populations.

\section{Can exclusion of vulnerable populations from beneficial research be unethical?}

Ethical principles requiring special justifications for research on vulnerable individuals were based upon an assumption that is not entirely true today. In the past it was presumed that all research subjects bear risks and burdens, making it a sacrifice to be selected. But, special benefits (sometimes of considerable worth) may be afforded to research subjects, which may make vulnerable persons and populations particularly eager to be selected. A fine line can be drawn between pure research and innovative treatment. For some poor groups, the only access to innovative therapies is by participation in research. To exclude vulnerable populations from participation in research may be to deny them their only realistic hope and promise of effective treatment and services.

A drug or vaccine that has not betn tested on poorer, more vulnerable populations may also prove more risky or less beneficial to them in future. The generalizability of research to vulnerable populations may require that those populations be involved in clinical trials. A decision to exclude vulnerable populations from research impedes scientific understanding about their health problems and the most promising interventions to meet their health needs.

Over-protection of vilnerable populations, therefore, may be paternalistic and ultimately harmful. A balance needs to be struck between protecting vulnerable people and providing them the benefit of therapeutic innovation. Overly strict ethical and legal limits placed on vulnerable persons to enter research can impede humanitarian investigation of problems relevant to their medical needs.

\section{Protecting the privacy of people and populations}

The concept of privacy is as complicated as human affect itself. Research subjects may claim a right to privacy on three levels: the right to have space in the physical, personal, or social sense (e.g., the absence of intrusive surveillance or questioning); a right to control the disclosure of information about their health, behavior or life circumstances (e.g. sexual or drug use history); and the right to mainiain intimacy and confidences in their personal, family or social relationships (e.g. their interactions with sexual partners, spouses, and professional counselors).

If sensitive information is linked to an individual it can cause him or her harm both of a tangible and intangible kind. It can result in the person being subjected to discrimination by employees, educators, landlords, or insurers (tangible harms); ${ }^{30}$, or it can result in a sense of personal violation, shame, or hurt (a wrong)."."

The ethical foundation for privacy is respect for the person. Respecting human beings means giving them the right to choose who has access to confidential information and under what circumstances. ${ }^{32}$ ' $\$$ means recognizing the legitimacy of personal secrets and allowing the individual to define what is secret and to control how secrets are used.33

The importance of privacy is underscored by the promises that researchers make, implicitly or explicitly, to keep information confidential. Research subjects come to think about investigators partly as clinicians, and they reasonably anticipate that their confidences will not be unreasonably disclosed. Each culture has its own mores about confidential information and relationships. It is incumbent upon researchers from other countries to learn about and be sensitive to local customs, and religious and personal beliefs about the sanctity of confidential information.

From a researcher's perspective, maintaining confidentiality has a utilitarian value. Recruiting and keeping human subjects will become much more difficult if researchers cannot ensure that information obtained as a consequence of the study will not be disclosed outside of the research team.

There are, of course, constant pressures to disclose the confidences of research subjects. Researchers may choose to disclose information in furtherance of their scientific purpose; they may be required to report the information to 
government agencies or sponsors; or they may receive a court order or subpoena to divulge the information for the administration of justice.

A breach of confidentiality does not occur if a competent adult gives informed consent, specifying the information that may be disclosed and to whom. Clear rules, however, are needed to govern effectively when disclosure can ethically occur in the absence of consent.

Three kinds of justification can be offered for divulging confidences obtained in the course of research. First, disclosure may be thought necessary to present a more credible or authoritative scientific report. A case study which does not disclose certain identifying characteristics may omit scientifically relevant information. In epidemiology, often the very object of the research is to obtain demographic, health or behavior related data. Restrictions on publication or other dissemination may defeat the very purpose of the research. A prior understanding about dissemination of information between the investigator and the individual and/or population can overcome confidentiality problems.

Second, disclosure may be thought necessary to protect the health and safety of others. The United States Tarasoff case ${ }^{34}$ created a legal duty on psychiatrists to disclose to a third party if a psychiatric patient poses an immediate and grave danger. The "duty to warn" may extend to third parties or populations who face a serious and imminent health risk - such as a sexual or needle sharing partner of a person infected with HIV, an environmental risk from hazardous waste, or the risk of disease from food or water contamination. Knowledge gained in epidemiologic research, then, may be nesessary to curtail a serious health risk to a population. Requirements to report instances of child abuse or communicable diseases to public health authorities also illustrate the need for disclosure for the protection of others. It is important in evaluating a "duty to warn" whether the health risk is serious and probable, or whether it is based upon a low probability of harm or even irrational fear or prejudice.

Finally, researchers may believe that disclosure is in the best interests of the research subject, such as when the subject needs medical treatment. One controversial issue is whether a mature minor deserves confidentiality when she seeks an abortion without informing the father or her family. Ordinarily, the principle of respect for persons requires the researcher to follow a competent person's own judgment about where his or her best interests lie.

Ethical principles of privacy and confidentiality are applicable to individual invasions, but need strengthening to safeguard adequately the privacy of populations. The potential for violating privacy rights is formidable where there is wide scale collection, transfer and use of information. Systematic gathering, reporting, and sharing of information about a group can be highly detrimental to the group and its members. The use of sophisticated computer technology to store and use personal data among countless sources only heightens the concern over privacy, stigmatization, and discrimination within populations. Capron emphasizes that information can be obtained from, and transferred to, government agencies (such as census, vital statistics, revenue collection, health, social services, and defense), schools, health care services and police."s

Data suggesting that particular groups are more likely to be infected with, and hence, capable of transmitting communicable or sexually transmitted diseases can reinforce prejudice and irrational fear of members of that group. Data which create or reinforce negative cultural stereotypes can be extremely hurtful. Examples of such data include research purporting to demonstrate that HIV originated in Africa, ${ }^{36}$ that homosexuals, drug abusers, and prostitutes spread sexual and blood borne disease, that mentally ill people are dangerous, or that certain races have less intelligence. Derogatory information associated with a group can result in real harms such as discrimination against members of the group in employment, housing, or insurance. Derogatory information can also cause intangible hurt to groups such as lowering their self-esteem and racial or cultural pride. Derogatory information about a sub-population can stigmatize and wound its people as much as breaches of confidentiality can affect an individual. The information collected from groups, just as the information about individuals, need not be blatant or intentional to cause harm or hurt. Even the best intentioned and careful research can trigger concerns about privacy.

Consider, for example, the widespread practice in the United States and elsewhere of reporting HIV seroprevalence data broken down by race and ethnicity. Although the data are collected for a valuable purpose and do not identify individuals, the method of reporting emphasizes the disproportionate impact on African Americans and Hispanics. A valid reason may, in fact, exist for so publicly characterizing race and ethnicity as risk markers (but not risk factors) for HIV, rather than using more neutral classifications such as socio-economic status or geographic area. The practice is so well entrenched, however, that no one asks whether the public health justification is significant enough to outweigh the potential impact on the dignity and self-esteem of the populations affected.

Even publicly available information, which the microethical principle of confidentiality often does not safeguard, takes on a new meaning when it is joined with information from a variety of sources. Some information, while technically "public" in the sense that it is theoretically available by, say, a freedom of information request or a national census, may hurt a person or a group by its public disclosure. Isolated facts by themselves may be innocuous, but when analyzed together with a chain of information, may reveal personal or group secrets. Thus, 
even if people agree to the release of particular information as an isolated event, they have not given meaningful consent unless they are aware of the totality of the collection and use of the information.

The ethical principle of privacy of populations, then, would view an entire pattern of collection and use of information, and not merely be concerned with unauthorized disclosure of an individual's research record.

Could individuals in a study each give consent to disclosure of information, and yet the study would violate the right of the collective to privacy? The answer is yes if one believes that populations have a right to defend their reputation and dignity as much as individuals do. It is conceivable, even where the information revealed about each member of the group is non-consequential or is not personally identifiable, that the group can be harmed. Blind seroprevalence studies, for example, raise few concerns about individual confidentiality because the name of the person is not identifiable. But the very purpose of the study is to obtain information about the population. To be sure, much of the information collected in good epidemiologic surveillance is potentially beneficial to the health of the community. Still, the power (whether intentional or inadvertent) to use the information in ways which undermine the dignity of the culture is always present. The right of populations to have some say in the collection and spread of data that they believe reflect badly on their identity is an important ethical principle.

\section{Distributive justice in international collaborative research}

The concept of justice is hardly foreign to the framework of ethics. "Justice" is an often used but seldom clearly defined term. It is frequently taken to mean that the benefits and burdens of research should be fairly distributed. This definition begs the question, for it does not explain what is fair or appropriate in allocating benefits and burdens. The legal concept of equal protection, more precisely, states that similarly situated individuals or classes of individuals should be treated equally, unless there is a relevant and compelling reason to treat them differently. ${ }^{37}$

This section suggests an entitlement to benefits, services, and resources which some traditional ethical thinkers may feel goes too far. Those who initiate, sponsor, and conduct research (including governments, funders, industry, and investigators) have an obligation to share the benefits of research not only with subjects while they are participating in a clinical trial, but with those subjects after the trial, as well as their communities.

Consider a case where researchers from the First World are undertaking a large field trial for a candidate vaccine or drug in the Third World. What responsibilities do they have to the subjects and the wider community during the trial, and what responsibilities do they have once the trial is over? Traditional ethical principles would certainly require protection of subjects while they are in the clinical trial, at least from any harms that may arise directly from their participation. This would mean that qualified clinicians would carefully observe any adverse effects of the research on subjects and provide immediate treatment. Once the drug or vaccine is shown to be efficacious, the study should cease so that those in the control group could be beneficially treated.

Taking ethical obligations further, do researchers have an obligation to confer benefits on research subjects which are not strictly relevant to the study? Many Northern/ Western researchers working in technologically developing countries provide prevention and health care services for the local community.

Investigators have a duty not merely to prevent harm to subjects, but to affirmatively protect their health and well-being by providing, within reasonable limits, prevention and health services. Research subjects should not be viewed as mere tools for the purposes of the research, but as whole persons with diverse health needs. In accordance with the principle of distributive justice, a primary ethical justification for selecting vulnerable populations for study is that benefits are conferred in exchange for their participation. This can include the direct benefits of the drug or vaccine provided in the study design, as well as risk reduction and health care services. Persons on the margins of survival give up productive time to contribute to the scientific endeavors of the research team. They can reasonably expect minimal services in return.

Once a person enters a research project, particularly if he or she is poor and lacks adequate access to medical care, the investigator assumes some duty of care to safeguard that person's health and welfare. Doctors involved in a trial cannot turn their backs on obvious illness and health care needs of trial participants.

From a utilitarian perspective, researchers have an interest in maintaining the health and welfare of subjects. Subjects who are healthy and satisfied are far more likely to be cooperative and reliable partners in research.

In addition to the arguments based upon equity and utility, it can also be argued that researchers should adhere to explicit or implicit promises. Unless the research team makes it otherwise clear, subjects expect that their basic health care needs will be met by health care professionals involved in the study. Subjects may not perceive the fine distinctions made by researchers between treating direct adverse effects of the drugs provided in the study design, and more general health care needs.

Ethical duties may extend after the study is complete. Is it ethical to summarily withdraw all health care services that the community has benefited from and come to expect, once the study is over? Some ongoing responsibility 
for subjects and communities extends beyond the temporal limits of the study. If research is viewed from the subjects', rather than solely from the investigators', perspective, a sense of loss and unmet expectations naturally occur the day after the research is completed and services are withdrawn. Sponsors and researchers who leave behind some continuing capacity to meet needs, even if at a reduced level, will help ensure receptivity to future research ideas and longer term health research planning.

Let us assume the results of the field trial are positive and the drug or vaccine is shown to be safe and effective. What is the responsibility of the research team to make the drug or vaccine available to the local population? A strong ethical responsibility exists to provide the efficacious agent to the subjects of the research. This requires that the agent is available as long as it is clinically appropriate. The World Health Organization consultation on candidate HIV vaccines said that justice requires that the "population in which the vaccine is tested is entitled to first priority in receiving the vaccine after its safety and efficacy have been established." 8 One might argue that it also includes the ancillary medical support and supervision necessary to monitor the adverse effects and toxicity of the agent.

Do other people in the local community have an ethical claim to the drug or vaccine? The choice of one subject over another in the community is often random and certainly unrelated to any morally rational choice. It would be inequitable if certain members of the population were to receive a benefit from which others were excluded. If Third World populations are to be used to create a health benefit for humankind, careful consideration should be given to making that benefit available to those who cannot afford it.

Why, it may be asked, are there affirmative ethical duties owed to local populations? The agreement required for international collaborative research is entered into not merely with subjects but with entire communities. Government and community leaders in host countries are consulted and provide permission for research. The understanding between collaborators may be that the community receives improved health services, as well as bearing any fruits that the research provides. By agreeing to become involved, research subjects and their communities anticipate that any knowledge, therapeutic agent, or vaccine that is advanced in the study will be used to improve their health.

Persons who sponsor and conduct research in Third World communities obtain a substantial benefit from the research. Investigators gain access to otherwise unavailable populations for research. Those populations bear the risks and burdens of research, the fruits of which will go to benefit many others. Industry may benefit financially from government subsidies in the development of a product. In some countries, industry is also permitted to set the price at whatever level it wishes. The commercial developers of new drugs or vaccines stand to make substantial profits in the marketplace. Arguments for making the product available more widely to the local population, then, are based upon the mutual exchange of benefits, and the equities of access to essential health improvements irrespective of the ability to pay.

Research conducted in the Third World sometimes can be inequitable in its allocation of benefits and burdens. All areas of the world benefit, for example, from the development of an efficacious vaccine or pharmaceutical. But a significant burden of experimentation rests on poorer Third World countries. At the same time, economic poverty and underdeveloped medical services realistically prevent Third World countries from buying and distributing beneficial preventive or therapeutic agents. ${ }^{39}$ It would be unjust if the populations which bear significant burdens of research were to reap the fewest rewards.

\section{Developing sound and enduring infra-structures}

Developing infra-structures in the host countries is an important objective of international collaborative research. Host countries can richly contribute both to local public health needs and to research objectives if their scientists and health care professionals are provided the resources and capacity to function as equal partners. Infra-structure building requires the development of high quality training and education, laboratory and other vital equipment, and prevention, health care, and hospital services.

The development of infra-structures provides stability for meeting ongoing public health and scientific needs. This is advantageous not only to host investigators and their institutions, but also to their collaborating partners in the North/West who will gain from ongoing relationships. A sound infra-structure that can endure through lengthy studies and enable future research to flourish emerges as an essential component of international public health planning and research.

\section{Ethical imperialism and ethical relativism}

"Ethical imperialism appears to be the imposition on one society of solutions culturally appropriate to another society, on the pretext that they represent ethical absolutes." 40 Certainly, no single country has the right to set universal standards to which other countries must comply. But, the foundation of international human rights from Nuremberg to Helsinki and beyond is the conviction that there is an irreducible set of international ethical standards common to all societies, which local law, politics, or custom cannot bend." ${ }^{4}$

Foundational principles for population-based research include: (I) the overriding imperative to protect the health 
and well-being of populations; (2) the right of populations to self-determination, including the right to refuse participation; (3) protection of vulnerable populations and the need for special justifications for research; (4) protecting the privacy, integrity, and self-esteem of populations; and (s) the equitable distribution of benefits and burdens of research. How these principles operate in practice requires an understanding of the mores of other people and places..$^{42}$

The purpose of this paper is to define a set of ethical principles which extend beyond the person dominated ethics of Helsinki to a view of ethics based upon the integrity of populations. In so doing, a deeper respect for, and toleration of, cultures steeped in the tradition of social relationships can be nurtured.

\section{References}

The author would like to thank the researchers and ethical thinkers on the WHO/CIOMS steering committee who assisted in the formulation of this paper, particularly Zbigniew Bankowski, Jay Bryant, Bernard Dickens, David Heymann, John Last, and Robert Levine.

I. National Commission for the Protection of Human Subjects of Biomedical and Behavioral Research. The Belmont Report: Ethical principles and guidelines for the protection of human subjects of research. Office of Protection from Research Risks, U.S. Public Health Service: Bethesda, Md., April I8, 1979; R.J. Levine, Ethics and Regulation of Clinical Research. Yale University Press: New Haven, 2d ed. 1988.

2. Nuremberg Code 1947, printed in Trials of War Criminals Before the Nuremberg Military Tribunals Under Control Council Law No. 10, vol. II (Washington, DC: U.S. Government Printing Office, 1949, at 181-182); World Medical Association Declaration of Helsinki: Recommendations Guiding Medical Doctors in Biomedical Research Involving Human Subjects, adopted by the 18 th World Medical Assembly, Helsinki, Finland, 1964, revised by the 29th WHA, Tokyo, Japan, 1975, and the 35 th WHA in Venice, Italy, 1983. Reprinted in Medical Ethics Declarations. World Medical Journal. 1984; 3 1:4; World Health Organization and Council for International Organizations of Medical Sciences. Proposed International Guidelines for Biomedical Research Involving Human Subjects. Geneva, 1982.

3. Law Reform Commission of Canada. Biomedical Experimentation Involving Human Subjects: Working Paper 61. Ottawa, 1989; U.S. Department of Health and Human Services Rules and Regulations, 45 CFR $46 \mathrm{C}$ (Revised as of March 8,1983); French Consel d'Etat. De l'ethique au droit. Paris 1988.

4. L. Gostin, "Collective and Individual Rights: Towards Resolving the Conflict." In: L. Gostin (ed), Civil Liberties in Conflict, Routledge: London and New York, 1988.

S. R.J. Levine, supra note I at $\mathbf{S 2 .}$

6. Geneva Declaration 1948, amended 1968, reprinted in

Medical Ethics Declarations. World Medical Journal $1984: 31: 3$. 7. O.O. Ajayi, "Taboos and Clinical Research in West

Africa," J. Med. Ethics 1980;6061-63.

8. The Belmont Report, supra note 1.

9. Nuremberg Code, supra note 1 , first principle.

10. Declaration of Helsinki, supra note 2 , article 1,9 .

1 1. WHO/CIOMS, supra note 2, at 23-24.

12. Council of Europe. Recommendation No. $\mathrm{R}(90)_{3} \mathrm{Con}$ - cerning Medical Research on Human Beings (6 Feb. 1990).

13. G.J. Hill, "Research on humans published in JAMA" (letter). J. Amer. Med. Assn. 1987; 258:1604.

14. E.O. Ekunwe and R. Kessel, "Informed Consent in the Developing World," Hastings Cen. Rep. 1984; 14:23-24.

1 5. U.S. Department of Health and Human Services, Rules and Regulations, 45 CFR 46 , para. 46.1 16 (Revised as of March $8,1983)$. Yet, some highly developed countries expressly reject the concept of informed consent. Sidaway v. Bethlehem Royal Hospital Governors [198 s] A.C. 871.

16. N.A. Christakis, "The Ethical Design of an AIDS Vaccine Trial in Africa." Hastings Center Rpt. 1988;1 8:31-37.

17. O.O. Ajayi, supra note 7; D. Adityanjee, "Informed Consent: Issues Involved for Developing Countries." Med. Sci. of Law 1986; 26: 305-307; WHO/CIOMS, supra note 2; R.J. Levine, "Validity of Consent Procedures in Technologically Developing Countries. In: Human Experimentation and Medical Ethics, "Z. Bankowski, N. Howard-Jones, eds. Geneva: CIOMS, 1982, pp. I 6-30.

18. Indian Council of Medical Research. Policy statement on ethical considerations involved in research on human subjects 1980; New Delhi, ICMR.

19. A.J. Hall, "Public Health Trials in West Africa: Logistics and Ethics." IRB 1989; $11: 8-10$.

20. Henderson et al., "Assessment of Vaccination Coverage, Vaccination Scar Rates and Small Pox Scarring in Five Areas of West Africa." Bull. WHO 1973;84:183-194.

2. O.O. Ajayi, supra note 7.

22. D. Adityanjee, supra note $17 ;$ O.O. Ajayi, supra note 7.

23. World Health Organization. Criteria for international testing of candidate HIV vaccines, 27 February - 2 March, 1989.

24. WHO/CIOMS, supra note 2.

25. WHO/CIOMS, supra note 2, paras, 14-15.

26. A.J. Hall, supra note $I 9$.

27. R.J. Levine, supra note 5 .

28. Centre for Human Rights, United Nations. The Rights of Indigenous Peoples. U.N.: Geneva, 1990.

29. J. Miller, "Towards an International Ethic for Research with Human Beings." IRB 1988; 10:9-1 1.

30. L. Gostin, "The AIDS Litigation Project: A National Review of Court and Human Rights Commission Decisions, Part II: Discrimination." J. Am. Med. Assn. 1990;263:20862093; PANOS Institute. The Third Epidemic: Repercussions of the fear of AIDS. 1990, PANOS, London.

31. T.L. Beauchamp, J. Childress, Principles of Biomedical Ethics. Oxford University Press, New York. 2nd ed. 1983.

32. R.J. Levine, supra note 5; H.C. Kelman, "Privacy and Research with Human Beings." J. Soc. Issues 1977; 33:169195.

33. S. Bok, "The Limits of Confidentiality." Hastings Ctr. Rpt. 1983;1 3:24-31.

34. Tarasoff v. Board of Regents of California (1976) 17 Cal.3d 452 (Tarasoff II), vacating 13 Cal. $3 \mathrm{~d}$ i 17 (Tarasoff I).

35. A. Capron, "Protection of Research Subjects: Do Special Rules Apply in Epidemiology." Paper presented at the IEF Conference on Ethics in Epidemiology, June 12-13, 1989, Birmingham, Alabama.

36. E. Tabor, R.J. Gerety, J. Cairns, A.C. Bayley, "Did HIV and HTLV Originate in Africa?" (letter). JAMA I 990; 264: $691-692$.

37. L. Gostin, "The Future of Public Health Law." Amer. J. Law or Med. 1987;1 2:461-490.

38. WHO, supra note 2.

39. N.A. Christakis, "Responding to a Pandemic: Interna- 


\section{Law, Medicine ơ Health Care}

tional Interests in AIDS Control." Daedalus 1989; 1 18:113134.

40. F. Gilks and J.B.O. Were, "Ethical Imperialism" (letter) N. Engl. J. Med. 1990; 322:200 41. M. Angell, "Ethical Imperialism? Ethics in Interna- tional Collaborative Clinical Research." N. Engl. J. Med. 1990; 319:108 I-1083.

42. M. Barry, "Ethical Considerations of Human Investigation in Developing Countries: The AIDS Dilemma." N.Engl. J. Med. 199; 319:1083-1086. 